\title{
Injury and frequency of use of playground equipment in public schools and parks in Brisbane, Australia
}

\author{
J W Nixon, C H C Acton, B Wallis, M F Ballesteros, D Battistutta
}

Injury Prevention 2003;9:210-213

\begin{abstract}
Objective: The purpose of this study was to determine the frequency of use of play equipment in public schools and parks in Brisbane, Australia, and to estimate an annual rate of injury per use of equipment, overall and for particular types of equipment.

Methods: Injury data on all children injured from playground equipment and seeking medical attention at the emergency department of either of the two children's hospitals in the City of Brisbane were obtained for the years 1996 and 1997. Children were observed at play on five different pieces of play equipment in a random sample of 16 parks and 16 schools in the City of Brisbane. Children injured in the 16 parks and schools were counted, and rates of injury and use were calculated.

Results: The ranked order for equipment use in the 16 schools was climbing equipment (3762 uses), horizontal ladders (2309 uses), and slides (856 uses). Each horizontal ladder was used 2.6 times more often than each piece of climbing equipment. Each horizontal ladder was used 7.8 times more than each piece of climbing equipment in the sample of public parks. Slides were used 4.6 times more than climbing equipment in parks and 1.2 times more in public schools.

The annual injury rate for the 16 schools and 16 parks under observation was $0.59 / 100000$ and $0.26 / 100000$ uses of equipment, respectively.

Conclusions: This study shows that annual number of injuries per standardized number of uses could be used to determine the relative risk of particular pieces of playground equipment. The low overall rate of injuries/100 000 uses of equipment in this study suggests that the benefit of further reduction of injury in this community may be marginal and outweigh the economic costs in addition to reducing challenging play opportunities.
\end{abstract}

Correspondence to:

Dr Jim Nixon, Department

Health, Royal Children's

Hospital, Herston, QID

4029, Australia

j.nixon@uq.edu.au

$\mathrm{F}$ alls from horizontal ladders are implicated in the greatest number of fracture injuries in playgrounds. ${ }^{1}$ The seriousness of injuries from such equipment has been reinforced in a clinical study which found $46 \%$ of children injured on "monkey bars" required surgery. ${ }^{2}$ It is not known whether the injury rate on this equipment is higher because it is more frequently used than other equipment or it is inherently more dangerous. A number of studies have made the assumption that playground equipment is used equally. ${ }^{13}$ Time spent playing over different surfaces has been studied, but exposure to different types of equipment has not. ${ }^{4}$

Injury prevention in playgrounds has focused on height of equipment, and the most effective surfaces to absorb energy when a child falls. ${ }^{35-8}$ Contribution to injury of equipment type can only be considered if the "exposure", or relative use of the equipment is known.

\section{MEASURES OF EXPOSURE TO RISK IN PLAYGROUNDS}

Three measures of exposure to playground surfaces and play have been reported. Injuries to children in childcare centres in Atlanta have been expressed as injuries per 100000 hours spent in childcare. ' Another approach to exposure used number of children and time spent playing over different play surfaces. ${ }^{4}$ The measure translated into an injury rate over grass of 12/10 000 child years. A third method of determining "exposure" was to count the number of children playing in each park visited by park inspectors. ${ }^{10}{ }^{11}$ This measure, while convenient, assumed that all play equipment was used equally by the children in the park, and examined children playing over different surfaces rather than the equipment played upon.

The purpose of this study was to estimate the annual rate of use of five types of playground equipment most likely to cause injury to children. Rate of use as a measure of exposure of children to risk of injury from playground equipment has not been reported previously.

\section{METHOD}

Approval for the study was obtained from the Royal Children's Hospital Ethics Committee, Brisbane. One requirement for the study was that two observers visit each site when observations were made.

\section{Equipment classifications}

Five types of equipment were observed: climbing equipment, horizontal ladders, track rides, slides, and swings. We recognize the potential for ambiguity in describing playground climbing equipment so our definition was inclusive rather than exclusive. In this study we included bridges of all heights and widths, cargo nets, whether chain or rope, flexible or rigid, fire poles, and ropes or chains for climbing as climbing equipment. Climbing equipment also included traditional tower frames, jungle gyms, igloo frames or more recent designs, where tunnels, corkscrew ladders, and other components were linked by platforms at different heights.

\section{Data collection}

Observations were undertaken in 16 randomly selected public park playgrounds and 16 public school playgrounds in the City of Brisbane. According to City of Brisbane park superintendents of the 725 parks from which the simple random sample was taken, 26\% were "high use", 36\%, "medium use", and 38\% "low use" parks. The sample drawn included six high use parks, five medium use parks, and five low use parks. The public school closest to the selected park was chosen for the school sample. Brisbane has 153 public schools with play equipment. 
Distribution of play equipment varied across the 725 parks and the sample. Two parks had two pieces of equipment only, and two parks had all of the five types represented with multiples of some types of equipment. The mean number of pieces of equipment for the 16 parks was 7.8, and the median 6.0. An inventory of all equipment in the City of Brisbane's 725 parks was obtained from the parks' administration. The sample drawn for parks under-represented climbing equipment and swings. Details of the total number or distribution of school play equipment were unavailable.

At least two observers used hand held counters and kept tallies of children using equipment in the 16 parks and 16 schools. A 30 minute observation and training session confirmed the method and reliability of the observers. The five types of equipment observed were those on which children were injured most frequently. Children were included in the tally if they climbed on the equipment at all. Even if a child climbed up the slide rather than the ladder, climbed the ladder of a slide, and climbed down without using the slide, they were counted. If a child touched the equipment without leaving the ground they were not included in the count. The count could represent one child using the equipment a number of times or a number of children using the equipment once each. The rationale for this approach was that a child is exposed to potential for injury each time equipment is used.

\section{Observations in schools}

Observations in schools were made during all opportunities for play on play equipment during the day. Those were during morning breaks and lunch breaks. Periods before and after school were not observed. Formal use of equipment was not permitted before or after school as these periods were not formally supervised. The school day began at 9.00 am and finished at $3.00 \mathrm{pm}$. Length of times available for play each day, and in which observations were made, ranged from 20 minutes to 70 minutes with a mean of 40 minutes. Some schools did not allow access to equipment during the short break and others limited access to certain grades, through the use of a daily roster. The formal play breaks produced the total monitored equipment use for the day.

A small number of swings and track rides in the sample were observed in schools. School playgrounds were undergoing refurbishment and older swings were being removed. Track rides were being introduced to schools and had a certain novelty value. Only one track ride and three swings occurred in the sample of schools.

Daily use of equipment was calculated for the 16 schools. A full school day's play was considered to be the time in one day that the children had supervised access to the equipment. Annual equipment use was estimated using 200 school days of which, on average, 152 were clear days according to Bureau of Meteorology records. As the total stock of equipment in the 153 public schools in Brisbane was not available, we estimated by extrapolating from the equipment in each school. Individual equipment injury-to-use rates were not calculated.

\section{Observations in public parks}

Four separate observations were made of each of the 16 parks. Observation periods were of one hour duration and included three weekdays and one weekend period. Weekday observations included one school vacation period and two observations on school days. Observations were made during spring, winter, and autumn. Observations were made during October/ November 1996, April, July, and August 1997.

An inventory of playground equipment for the City was obtained from equipment records of the Brisbane City Council Administration in order to estimate city wide use of equipment.

An average daily use was estimated for each piece of equipment. It was based on four hours of observation of each of five pieces of equipment in 16 parks. It was conservatively assumed that there were eight hours a day in which play equipment could be used. Observations were made to include all times between 8:30 am and 5:30 pm. The sun sets in Brisbane before $5 \mathrm{pm}$ in mid-winter and before $7 \mathrm{pm}$ in mid-summer. There was no formal supervision in public parks.

\section{Injury data}

Injury data were obtained from children attending the Royal Children's Hospital and the Mater Children's Hospital for medical attention in Brisbane, Australia. Data were obtained for the years 1996-97. All children injured and attending one of the hospitals for treatment after playground equipment injury were included, and children injured in any of the 16 parks or 16 schools in the period 1996-97 were noted. Injury data were obtained from medical records, from a questionnaire, and interview with parents or carers attending the child. Playground falls were rarely witnessed by an independent observer.

Case selection was complete for the two public children's hospitals. Children attending private hospitals were not included in this study. Informal, but informed estimates suggest that private facilities might see as many as $10 \%$ of the number seen in public emergency departments.

The average annual number of children injured and attending hospital for treatment after injury involving horizontal ladders, climbing equipment, slides, and swings in parks and schools was calculated using the formula "number of injuries $\times$ number of equipment uses per annum divided by $100000 "$.

\section{RESULTS}

\section{Schools}

During the two years of data collection 117 children were injured on public school equipment and sought medical attention at one of the children's hospitals. Thirteen of these children were injured on equipment in schools in the sample of 16 schools. The number of injured children expected in the sample of 16 schools was 12.2 (if there were 117 injuries in 153 schools) over the two year period.

Table 1 shows the five main types of equipment on which children in the Brisbane population were injured, the annual number of injuries in the population, and the distribution of equipment in the sample of 16 schools. Horizontal ladders produced $52.1 \%$ of injuries (5.5/year in schools) in the sample, while that equipment comprised $15.9 \%$ of the equipment in the sample.

Table 2 shows the use of equipment per day and the average use of each piece of equipment in the sample of public schools. Horizontal ladders were the most heavily used piece of equipment in public schools (excluding track rides). The single track ride in the sample of schools was used constantly (333 times in 50 minutes of observation, an average of once every nine seconds) during the observation period. Occasionally children were seen to have two riders on the track ride at the one time.

Assuming $152(0.76 / 40$ weeks $\times 5$ school days have less than $1 \mathrm{~mm}$ rain, Bureau of Meteorology figures) clear school days, the annual injury rate on the five types of equipment for the 16 schools observed was $0.59 / 100000$ uses of the equipment.

\section{Parks}

Table 1 also shows the distribution of injuries for the Brisbane population and those children injured in the sample of 16 parks. The table also shows the numbers of pieces of equipment included in the random sample. Horizontal ladders produced the greatest number of injuries in community parks; however, they were not widely distributed in the sample. The average annual number of injured children in the sample of 16 parks was 3.5 children. 
Table 1 Children injured on five types of playground equipment in public schools and parks and attending children's hospitals in Brisbane, and the distribution of play equipment in a sample of 16 parks and 16 schools

\begin{tabular}{|c|c|c|c|c|c|c|}
\hline \multirow[b]{2}{*}{ Equipment } & \multicolumn{2}{|c|}{$\begin{array}{l}\text { No }(\%) \text { of injured } \\
\text { children/annum in } \\
\text { population }\end{array}$} & \multicolumn{2}{|c|}{$\begin{array}{l}\text { No (\%) of injured } \\
\text { children/annum in } \\
\text { sample }\end{array}$} & \multicolumn{2}{|c|}{$\begin{array}{l}\text { No (\%) of pieces of } \\
\text { equipment in sample }\end{array}$} \\
\hline & Schools & Parks & Schools & Parks & Schools & Parks \\
\hline Horizontal ladder & $30.5(52.1)$ & $19(38.4)$ & $5.5(84.6)$ & 1 & 17 (15.9) & $5(4.0)$ \\
\hline Climbing equipment & $15(25.6)$ & $11(22.2)$ & $1(15.4)$ & 1.5 & 72 (67.3) & 57 (46.0) \\
\hline Slide & $7.5(12.8)$ & $6(12.1)$ & 0 & 1 & 14 (13.1) & $24(19.4)$ \\
\hline Track ride & $4.5(7.7)$ & $7.5(15.2)$ & 0 & 0 & $1(0.9)$ & $2(1.6)$ \\
\hline Swing & $1(1.8)$ & $6(12.1)$ & 0 & 0 & $3(2.8)$ & $36(29.0)$ \\
\hline Total & $58.5(100.0)$ & $56.5(100.0)$ & $6.5(100.0)$ & $3.5(100.0)$ & $107(100.0)$ & 124 (100.0) \\
\hline
\end{tabular}

Table 2 Average use per piece of equipment observed in 16 randomly selected schools in the city of Brisbane with number of uses observed per day, and the distribution of equipment over the 16 schools

\begin{tabular}{llll}
\hline Equipment & $\begin{array}{l}\text { No of pieces } \\
\text { of equipment } \\
\text { in sample }\end{array}$ & $\begin{array}{l}\text { Total number } \\
\text { of uses per } \\
\text { day }\end{array}$ & $\begin{array}{l}\text { Average use } \\
\text { per day for } \\
\text { each piece of } \\
\text { equipment }\end{array}$ \\
\hline $\begin{array}{l}\text { Horizontal ladder } \\
\text { Climbing }\end{array}$ & 17 & 2309 & 136 \\
equipment & 72 & 3762 & 52 \\
$\begin{array}{l}\text { Slide } \\
\text { Track ride }\end{array}$ & 14 & 856 & 61 \\
$\begin{array}{l}\text { Swing } \\
\text { Total }\end{array}$ & $1^{*}$ & 333 & $*$ \\
\hline
\end{tabular}

${ }^{*}$ Average use not calculated as the number of pieces of equipment was small and track ride use was considered abnormal.

Table 3 Distribution of play equipment in sample of public parks, number of observed uses of equipment, and average use of each type of equipment per day

\begin{tabular}{lllll}
\hline & $\begin{array}{l}\text { No of } \\
\text { pieces of } \\
\text { equipment } \\
\text { in sample }\end{array}$ & $\begin{array}{l}\text { No of } \\
\text { uses in } \\
\text { obserr } \\
\text { obsuipment }\end{array}$ & $\begin{array}{l}\text { No of } \\
\text { uses in } \\
\text { an } 8 \\
\text { hour day }\end{array}$ & $\begin{array}{l}\text { Average } \\
\text { use per } \\
\text { piece } \\
\text { per day }\end{array}$ \\
\hline Horizontal ladder & 5 & 390 & 780 & 156 \\
Climbing equipment & 57 & 566 & 1132 & 20 \\
Slide & 24 & 1104 & 2208 & 92 \\
Track ride & 2 & 69 & 138 & 69 \\
Swing & 36 & 343 & 686 & 19 \\
All equipment & 124 & 2472 & 4944 & \\
\hline
\end{tabular}

Table 3 shows the number of times the equipment was used by children playing in public parks during four hours of observation. The average use of each piece of equipment is also shown. Each horizontal ladder was used more than any other piece of equipment in the sample. Each slide was used over four times more than climbing equipment but there were almost twice as many slides and pieces of climbing equipment as there were horizontal ladders. We have assumed 276 clear days for play ( $76 \%$ of 365 days where less than $1 \mathrm{~mm}$ rain fell, Bureau of Meteorology daily rainfall analysis). The annual injury rate for the five types of equipment in the 16 parks observed was $0.26 / 100000$ uses.

\section{DISCUSSION}

\section{Schools}

Each horizontal ladder was used more than any other single piece of equipment (excluding the single, much used track ride). Because the distribution of equipment in the school population was unknown, it has not been possible to compare the distribution of equipment within the sample of schools. We have not estimated injury/use rates for individual pieces of equipment because the distribution of individual equipment in the population was not known.

The use of the single track ride observed in a school was greater than for any single piece of equipment. It had constant use, constant queuing, and pressure on the participants to keep moving. Track rides were introduced to schools for the first time during the period of the study. The novelty of the equipment may have contributed to high use. Track rides made up $7.8 \%$ of injuries from $0.9 \%$ of the equipment in city parks.

Horizontal ladders had the highest number or rate of injuries and greatest amount of use. We have observed and spoken to children about a game played on horizontal ladders. In this game children take turns to jump from the mounting ladder or platform to catch alternate bars on the horizontal ladder, increasing the number of bars they miss each turn. The winner catches the furthest bar. Inevitably children miss the bar. Play behaviour has been considered in at least one observation study of children and parents or caretakers in playgrounds. ${ }^{12}$ Specific studies related to risk behaviour or incorrect use of the equipment and its association with injury have yet to be undertaken.

\section{Parks}

Horizontal ladders were used more than any other single piece of equipment. However, it was also among the least likely type of equipment to be installed in parks and as a consequence slides and swings were more frequently used overall in the sample of parks.

\section{Differences in parks and schools}

Unlike play in parks, play in schools occurred in a defined, compressed period during breaks. School aged children spend time on park equipment after school, at weekends, and vacation time. In schools we observed all play for the day, while in parks we sampled across the whole day's play. The difference in method may have produced a sampling error.

Supervision in schools included a schedule of children of different grades to use the equipment at different times. In this study, children in the peak age groups for injury (5-9 year olds) were timetabled to use the equipment $70 \%$ of the time under observation. Apart from all play being concentrated into a short play period in schools each day, more children were likely to be using the equipment at any one time than in parks. Queues would form, and, although schools limited the number of children on equipment, children in the queue would encourage speedy use in others. Differences in the manner of play could be associated with different rates of injury observed between schools and parks. 
In the small number of parks and schools where a full range of equipment was available, and therefore children had choices, horizontal ladders were popular. Track rides too were popular, although frequency of installation was too small to draw any conclusions about the population. Injuries from track rides could be expected to increase as further installation takes place.

\section{Limitations}

Not having an inventory of equipment in school playgrounds limited our capacity to confirm the distribution of equipment in the sample of schools. Our estimate of expected injuries in the sample of schools, compared with the actual injuries in the sample of school playgrounds, suggested confidence in the results at a school level. However, as the distribution of equipment in all schools was unknown, we did not consider estimates of injury-to-use rates advisable for individual types of equipment.

The number of parks in the sample $(2.2 \%)$ is small, but more importantly, the equipment within those parks was not representative of equipment across all parks. For this reason we have not calculated rates of injuries/use for individual equipment.

The selection of parks and schools as the unit of study led to distortions in the distribution of individual types of equipment in the sample. It is not known whether the discrepancies between the sample and the inventory in parks relate to the distribution of less numerous equipment such as track rides or to the inventory of equipment in a time of change and upgrade of equipment.

This study included observations staggered over school days and weekends, holidays, time of day, different seasons, and produced an annual picture of use. Ideally sex and age of children would be considered. We believe that video recording could enhance the data collection and allow reliability and validity checks of the observations; however, permission to video children at play could not be obtained..$^{13}$

In preliminary observations we realized that children's play in playgrounds is often fast and that the time spent on any particular equipment might be from several seconds in the case of horizontal ladders and track rides to several minutes or longer on some climbing equipment. We also recognized that climbing equipment might take the form of a bridge or a tower or other various distinct components and that time spent on these would need to be addressed individually as separate components. A limitation of this study was that ages of children using equipment could not be determined in an observation only setting.

The discrepancy in the installation of climbing equipment between parks and schools highlights an important consideration in definition of climbing equipment and its component parts. We counted the individual components of climbing equipment in parks and schools visited. The count for climbing equipment in all parks was undertaken by contacting manufacturers to find the number and types of components in the named equipment in the list provided by the parks administration. This process could have lead to miscounting of components. Emergency department data do not usually distinguish different components or type of climbing equipment. Clearer definitions of climbing equipment are essential in data indicating which equipment was involved in an injury and are equally important in ascertaining community use of play equipment.

\section{CONCLUSIONS}

Play is a critical element of child growth and development ${ }^{14}$ and opportunities to increase play must be balanced with concerns for safety. This study shows that injuries per number

\section{Key points}

- Horizontal ladders produce more injuries than other play equipment but they were also the most used piece of equipment in public schools and parks.

- The overall rate of injuries per number of uses of equipment was low.

- Intervention to reduce injury should consider children's need for exercise and play, and recognise the popularity and challenges of different types of equipment.

of uses of playground equipment could be used to determine the relative risk of particular pieces of playground equipment. Horizontal ladders produced the majority of injuries, but they were also the most used piece of equipment in both parks and schools.

The overall rate of injuries ( 0.59 schools and 0.26 parks) per 100000 uses of equipment was low. Intervention measures to further reduce injury in this community should consider the popularity among children of particular equipment, children's developmental needs for play, and the effects of changing playground equipment at the expense of reducing challenging play opportunities.

\section{ACKNOWLEDGEMENTS}

This research is a project of Injury Prevention and Control Australia Ltd supported by grants from South East Queensland Regional Organization of Councils (SEQROC), Education Queensland, and the NHMRC. We acknowledge the cooperation of The Queensland Injury Surveillance Unit and the Emergency Departments of the Royal Children's Hospital and the Mater Children's Hospital.

\section{Authors' affiliations}

J W Nixon, C H C Acton, B Wallis, Department of Paediatrics and Child Health, University of Queensland, Brisbane, Australia

J W Nixon (Visiting Fellow), M Ballesteros, National Center for Injury Prevention and Control, Centers for Disease Control and Prevention, Atlanta, USA

D Battistutta, School of Public Health, Queensland University of Technology, Brisbane, Australia

\section{REFERENCES}

1 Mott A, Rolfe K, James R, et al. Safety of surfaces and equipment for children in playgrounds. Lancet 1997;349:1874-6.

2 Waltzman ML, Shannon M, Bowen AP, et al. Monkeybar injuries: complications of play. Pediatrics 1999;103(5):e58.

3 Laforest S, Robitaille $Y$, Lesage D, et al. Surface characteristics, equipment height, and the occurrence and severity of playground injuries. Inj Prev 2001;7:35-40.

4 Sosin DM, Keller P, Sacks JJ, et al. Surface-specific fall injury rates on Utah school playgrounds. Am J Public Health 1993;83:733-5.

5 Lewis LM, Naunheim R, Standeven J, et al. Quantitation of impact attenuation of different playground surfaces under various environmental conditions using a tri-axial accelerometer. J Trauma 1993;35:932-5.

6 Chalmers DJ, Marshall SW, Langley JD, et al. Height and surfacing as risk factors for injury in falls from playground equipment: a case-control study. Inj Prev 1996;2:98-104.

7 Mack MG, Sacks JJ, Thompson D. Testing the impact attenuation of loose-fill playground surfaces. Inj Prev 2000;6:141-4.

8 Macarthur C, Hu X, Wesson DE, et al. Risk factors for severe injuries associated with falls from playground equipment. Accid Anal Prev 2000;32:377-82

9 Sacks JJ, Smith JD, Kaplan KM, et al. The epidemiology of injuries in Atlanta day-care centers. JAMA 1989;262:1641-5.

10 Sibert J, Mott A, Rolfe K, et al. Preventing injuries in public playgrounds through partnership betwen health services and local authority: community intervention study. BM 1999:318:1595.

11 Mott A, Evans R, Rolfe K, et al. Patterns of injuries to children on public playgrounds. Arch Dis Child 1994;71:328-30.

12 Morrongiello BA, Dawber T. Mothers' responses to sons and daughters engaging in injury-risk behaviors on a playground: implications for sex differences in injury rates. J Exp Child Psychol 2000;76:89-103.

3 Coppens NM, Gentry LK. Video analysis of playground injury-risk situations. Res Nurs Health 1991;14:129-36.

14 Sleet D. Play...in all seriousness. Society and Leisure 1974;3:143-6. 